\title{
Efeito da Relação Arginina:Lisina sobre o Desempenho e Qualidade de Carcaça de Frangos de Corte de 3 a 6 Semanas de Idade, em Condições de Alta Temperatura ${ }^{1}$
}

\author{
Fernando Guilherme Perazzo Costa ${ }^{2}$, Horacio Santiago Rostagno ${ }^{3}$, Rodrigo Santana Toledo ${ }^{4}$, \\ Luiz Fernando Teixeira Albino ${ }^{3}$
}

RESUMO - Foi realizado um experimento com 720 frangos de corte machos Ross, mantidos em alta temperatura ambiente $(26,2$ a $30,5^{\circ} \mathrm{C}$ ), na fase de crescimento ( 22 a 42 dias de idade), com o objetivo de estudar o efeito da relação arginina:lisina digestível (Arg:Lis) sobre o desempenho e a qualidade de carcaça de frangos de corte. Foi utilizado um delineamento inteiramente casualizado com seis tratamentos $(95,0 ; 102,5 ; 110,0 ; 117,5 ; 125,0 ;$ e 132,5\% da relação Arg:Lis na ração), seis repetições por tratamento e 20 aves por unidade experimental. Não houve efeito significativo dos tratamentos no desempenho de frangos de corte, entretanto, à medida que aumentou a relação Arg:Lis, houve efeito linear crescente para o rendimento de perna e decrescente para a gordura abdominal.

Palavras-chave: arginina, alta temperatura, frangos de corte, lisina

\section{Influence of Arginine:Lysine Ratio on Performance and Carcass Quality of Broilers from 3 to 6 Weeks of Age under High Temperature}

\begin{abstract}
An experiment was run using 720 male Ross chicks, grown from 22 to 42 days of age under high environmental temperature condition $\left(26.2\right.$ to $\left.30.5^{\circ} \mathrm{C}\right)$, to evaluate the effect of the digestible arginine:lysine (Arg:Lys) ratio on performance and carcass quality of broiler chickens. A complete randomized design with six treatments (95.0, 102.5, 110.0, 117.5, 125.0 and 132.5\% Arg:Lys ratio), six replicates and 20 birds per experimental unit was used. There was no significant effect on broiler performance, however Arg:Lys ratio linearly improved leg quarter yield and linearly decreased abdominal fat.
\end{abstract}

Key Words: arginine, broilers, high temperature, lysine

\section{Introdução}

Os efeitos da temperatura ambiental sobre o crescimento, consumo de ração e qualidade de carcaça de frangos de corte são bem conhecidos (LEESON, 1986).

Há evidências de que ocorra considerável grau de antagonismo entre a arginina e lisina. Segundo AUSTIC (1981), antagonismo é uma interação que envolve aminoácidos estruturalmente semelhantes, sendo que o excesso de cada um deles eleva a exigência do outro. A arginina é um aminoácido essencial considerado um dos mais limitantes em dietas à base milho e farelo de soja para aves (EDMONDS et al., 1985). As aves por não apresentarem o ciclo da uréia funcional, apresentam a exigência de arginina bem maior que os mamíferos (BAKER, 1991). ALLEN e BAKER (1972) mostraram que a exigência de arginina é aumentada pelo excesso de lisina na dieta. Balnave e Oliva (1991), citados por BRAKE et al. (1998), verificaram que a digestibilidade da arginina diminuiu significativamente com o aumento da temperatura ambiente enquanto que não afetou a digestibilidade da lisina. MENDES et al. (1997) verificaram que o aumento da relação Arg:Lis melhorou a conversão alimentar e o rendimento de carcaça e reduziu a gordura abdominal em frangos de corte, criados sob diferentes condições ambientais (quente, neutro e frio).

Em condições de temperatura normal, a relação arginina:lisina recomendada é de 110\% (NATIONAL RESEARCH COUNCIL - NRC, 1994) na base de aminoácido total e de $112 \%$ (MACK et al., 1999) e $108 \%$ (ROSTAGNO et al., 2000), quando apresentada na base de aminoácidos digestíveis verdadeiros.

Este trabalho foi realizado com o objetivo de estudar o efeito da relação arginina:lisina digestível sobre o desempenho e a qualidade de carcaça de frangos de corte criados em ambiente de alta temperatura durante o período de 22 a 42 dias de idade.

\footnotetext{
${ }^{1}$ Experimento desenvolvido durante o curso de Doutorado em Zootecnia na UFV.

${ }^{2}$ Professor do DZO/UFPB. E.mail: fperazzo@cca.ufpb.br

3 Professor do DZO/UFV.

${ }^{4}$ Estudante do curso de Mestrado de Zootecnia-Viçosa-MG-36571-000.
} 


\section{Material e Métodos}

Foram utilizados 720 frangos de corte machos, da linhagem Ross, de 22 dias de idade, em delineamento inteiramente casualizado com seis relações diferentes de arginina:lisina digestível $(95,0 ; 102,5 ; 110,0$; 117,$5 ; 125,0 ;$ e $132,5 \%$ ) e $3200 \mathrm{kcal} / \mathrm{kg}$ de EM, com seis repetições de 20 aves por unidade experimental, totalizando 36 boxes.

Para a obtenção das crescentes relações Arg:Lis, foi adicionado L-Arginina à ração basal em substituição ao amido (Tabelas 1 e 2). Os valores analisados de lisina e de arginina foram semelhantes aos calculados utilizando dados de Tabelas de Composição (NRC, 1994 e ROSTAGNO et al, 2000).

As variáveis consideradas foram analisadas de acordo com o seguinte modelo estatístico:

$$
\mathrm{Y}_{\mathrm{ik}}=\mu+\mathrm{T}_{\mathrm{i}}+\mathrm{e}_{\mathrm{ik}}
$$

em que: $Y_{i j k}=$ observação referente ao animal ${ }_{k}$, que recebeu o tratamento ${ }_{i} ; \mu=$ média geral; $T_{i}=$ efeito do tratamento; $\mathrm{e}_{\mathrm{ik}}=$ erro aleatório associado a cada observação.

As aves foram alojadas em galpão de alvenaria dividido em boxes de $1,5 \mathrm{~m}$ x 1,5 m, com cama de maravalha e o fornecimento de ração e água ad libitum. O programa de luz adotado foi o contínuo com 24 horas de luz (natural + artificial), durante todo o período experimental.

As aves foram pesadas no início e no final do período experimental para determinação do ganho de peso. Da mesma forma, o consumo de ração foi calculado considerando-se a ração fornecida e as sobras das rações dos comedouros. Posteriormente, calculou-se a conversão alimentar pela razão entre o consumo de ração e o ganho de peso das aves. A temperatura e umidade relativa foram determinadas através de medições diárias em termômetros de bulbo seco e bulbo úmido, respectivamente.

No $42^{\circ}$ dia de idade das aves, foram avaliados o ganho de peso, consumo de ração, conversão alimentar. Em seguida, após jejum de 6 horas, foram abatidas quatro aves de cada unidade experimental (peso médio do boxe) para avaliação do rendimento de carcaça, rendimento de perna (coxa + sobrecoxa), rendimento de peito com osso e pele, rendimento de filé de peito e gordura abdominal. A gordura abdominal foi considerada com o tecido adiposo contido ao redor da cloaca, da Bursa de Fabricius e dos músculos abdominais adjacentes,
Tabela 1 - Composição da ração basal

Table 1 - Composition of basal diet

\begin{tabular}{|c|c|}
\hline $\begin{array}{l}\text { Ingrediente } \\
\text { Ingredient }\end{array}$ & $\begin{array}{l}\text { Tratamento } 1 \\
\text { Treatment } 1\end{array}$ \\
\hline Milho & 49,725 \\
\hline Corn & \\
\hline Sorgo baixo tanino & 15,000 \\
\hline Sorghum low tannin & \\
\hline Farelo de soja & 23,400 \\
\hline Soybean meal & \\
\hline Farelo de glúten milho & 3,300 \\
\hline Corn glúten meal & \\
\hline Óleo de soja & 3,670 \\
\hline Soybean oil & \\
\hline Fosfato bicálcico & 1,750 \\
\hline Dicalcium phosphate & \\
\hline Calcário & 1,250 \\
\hline Limestone & \\
\hline Sal & 0,400 \\
\hline Salt & \\
\hline L-Lisina HCL 99\% & 0,370 \\
\hline L-Lysine HCL 99\% & \\
\hline DL-Metionina 99\% & 0,230 \\
\hline DL-Methionine $99 \%$ & \\
\hline L-Treonina 98,5\% & 0,080 \\
\hline L-Threonine $98,5 \%$ & \\
\hline L-Arginina $99 \%$ & variável \\
\hline L-Arginine $99 \%$ & \\
\hline $\begin{array}{l}\text { Suplemento mineral, vitamínico e aditivo }{ }^{2} \\
\text { Premix mineral, vitaminic and additive } e^{2}\end{array}$ & 0,325 \\
\hline Amido & 0,500 \\
\hline Starch & \\
\hline Total & 100,00 \\
\hline
\end{tabular}

1 Todas as dietas foram calculadas para conter: $3200 \mathrm{kcal} / \mathrm{kg}$ de EM; $18,50 \%$ de Proteína; $1,15 \%$ Lis.; 0,857\% Met.+Cis.; 0,783\% Tre; $0,99 \%$ Ca; 0,43\% P Disponível e 0,20\% Na.

All diets were calculated to have: $3200 \mathrm{kcal} / \mathrm{kg} \mathrm{ME;} 18.50 \%$ Protein; $1.15 \mathrm{Lys}$; $0.857 \%$ Met. + Cys.; $0.783 \%$ Thre; $0.99 \%$ Ca; $0.43 \%$ available $P$ and $0.20 \%$ Na.

* Níveis de suplementação de vitaminas, minerais e aditivos, quantidade por $\mathrm{kg} / \mathrm{ração} \mathrm{(Suplementation} \mathrm{levels} \mathrm{vitamins,} \mathrm{minerals} \mathrm{and}$ additives levels, amount by kg/feed): Vit. A, $10.000 \mathrm{UI}$; Vit. $\mathrm{D}_{3}, 2.000 \mathrm{UI}$; Vit. E, 30 UI; Vit. $B_{1}, 2$ mg; Vit. $B_{6}, 3 \mathrm{mg}$; Vit. $B_{12}, 0,015 \mathrm{mg}$; Ac. Pantotênico (Pantotenic acid), $12 \mathrm{mg}$; Biotina (Biotin), 0,10 mg; Vit. $\mathrm{K}_{3}$, 3 mg; Ácido fólico (Folic acid), 1,0 mg; Ácido nicotínico (Nicotinic acid), $50 \mathrm{mg}$; Cloreto de colina 60\% (Choline choride), $100 \mathrm{~g}$; Antioxidante (Antioxidant), 1,0 mg (BHT); Selênio (Selenium), 0,25 g; salinomicina (salinomycin), $66 \mathrm{mg}$; virginiamicina (virginiamycin), $10 \mathrm{mg}$; Manganês (manganese), $106 \mathrm{~g}$; Ferro (Iron), $100 \mathrm{~g}$; Cobre (Copper), $20 \mathrm{mg}$; Cobalto (Cobalt), 2 mg; lodo (lodine), 2 mg; Zinco (Zinc), 50 mg.

conforme descrito por SMITH (1993). O rendimento dos cortes foi calculado em relação ao peso da carcaça eviscerada.

As análises estatísticas das características estudadas foram realizadas utilizando-se o programa SAEG (Sistema para Análises Estatísticas e Genéticas), desenvolvido pela UNIVERSIDADE FEDERAL DE VIÇOSA - UFV (1983). 
Tabela 2 - Composição das rações experimentais

Table 2 - Composition of the experimental diets

\begin{tabular}{|c|c|c|c|c|c|c|}
\hline & \multicolumn{6}{|c|}{$\begin{array}{l}\text { Tratamentos } \\
\text { Treatments }\end{array}$} \\
\hline & 1 & 2 & 3 & 4 & 5 & 6 \\
\hline Ração basal & 99,500 & 99,500 & 99,500 & 99,500 & 99,500 & 99,500 \\
\hline Basal diet & & & & & & \\
\hline L-Arginina $99 \%$ & 0,000 & 0,081 & 0,162 & 0,242 & 0,323 & 0,404 \\
\hline $\begin{array}{l}\text { L-Arginine } \\
\text { L-Arginina } 99 \% 2 \\
\text { L-Arginine } 99 \%{ }^{2}\end{array}$ & $(0,000)^{2}$ & $(0,093)^{2}$ & $(0,176)^{2}$ & $(0,250)^{2}$ & $(0,348)^{2}$ & $(0,414)^{2}$ \\
\hline Amido & 0,500 & 0,419 & 0,338 & 0,258 & 0,177 & 0,096 \\
\hline & & $\begin{array}{l}\text { Compe } \\
\text { Calculd }\end{array}$ & $\begin{array}{l}\text { ição calculada } \\
\text { ed and analyzed }\end{array}$ & $\begin{array}{l}\text { analisada } \\
\text { mposition }\end{array}$ & & \\
\hline $\begin{array}{l}\text { Proteína bruta } \\
\text { Crude protein }\end{array}$ & $18,5(19,3)^{2}$ & $18,5(19,0)^{2}$ & $18,5(19,4)^{2}$ & $18,5(19,7)^{2}$ & $18,5(19,3)^{2}$ & $18,5(19,9)^{2}$ \\
\hline $\begin{array}{l}\text { Arginina total } \\
\text { Total arginine }\end{array}$ & $1,11(1,12)^{2}$ & $1,19(1,19)^{2}$ & $1,27(1,27)^{2}$ & $1,35(1,33)^{2}$ & $1,43(1,38)^{2}$ & $1,51(1,50)^{2}$ \\
\hline $\begin{array}{l}\text { Arginina digestível } \\
\text { Digestible arginine }\end{array}$ & 1,000 & 1,080 & 1,160 & 1,240 & 1,320 & 1,400 \\
\hline $\begin{array}{l}\text { Lisina total } \\
\text { Total lysine }\end{array}$ & $1,15(1,16)^{2}$ & $1,15(1,17)^{2}$ & $1,15(1,15)^{2}$ & $1,15(1,13)^{2}$ & $1,15(1,13)^{2}$ & $1,15(1,18)^{2}$ \\
\hline $\begin{array}{l}\text { Lisina digestível } \\
\text { Digestible lysine }\end{array}$ & 1,053 & 1,053 & 1,053 & 1,053 & 1,053 & 1,053 \\
\hline $\begin{array}{l}\text { Relação arg:lis dig. } \\
\text { Dig. Arg:Lys ratio }\end{array}$ & 95,0 & 102,5 & 110,0 & 117,5 & 125,0 & 132,5 \\
\hline
\end{tabular}

2 Valores analisados (Analyzed values).

\section{Resultados e Discussão}

As médias da temperatura e da umidade relativa do ar registradas durante o período experimental são apresentadas na Tabela 3.

Não houve efeito significativo $(\mathrm{P}>0,05)$ do aumento da relação Arg:Lis sobre o desempenho das aves criadas em condições de alta temperatura ambiente (Tabela 4). MENDES et al. (1997) e BRAKE et al. (1998), conduzindo pesquisas semelhantes, não detectaram melhora no ganho de peso das aves, entretanto, observaram melhor conversão alimentar à medida que se aumentou a relação Arg:Lis em condições de alta temperatura ambiente. Vale ressaltar, no entanto, que numericamente os melhores valores de desempenho foram obtidos com a relação Arg:Lis. digestível de 110\%, valores estes próximos à relação preconizada por $\mathrm{MACK}$ et al. (1999) e ROSTAGNO et al. (2000).

$\mathrm{O}$ rendimento de carcaça, peito com pele e osso e filé de peito não foram influenciados $(\mathrm{P}>0,05)$ pelo aumento da relação Arg:Lis. O rendimento de perna (coxa + sobrecoxa) foi significativamente influenci- ado $(\mathrm{P}<0,05)$, melhorando linearmente com o aumento da relação Arg:Lis. A gordura abdominal foi significativamente afetada $(\mathrm{P}<0,05)$, reduzindo linearmente com o aumento da relação Arg:Lis (Tabela 5).

Tabela 3 - Condições ambientais durante o período experimental

Table 3 - Environmental conditions during the experimental period

\begin{tabular}{|c|c|c|c|c|}
\hline \multirow[t]{2}{*}{$\begin{array}{l}\text { Dias } \\
\text { Days }\end{array}$} & \multicolumn{2}{|c|}{$\begin{array}{l}\text { Temperatura }\left({ }^{\circ} \mathrm{C}\right) \\
\text { Temperature }\left({ }^{\circ} \mathrm{C}\right)\end{array}$} & \multicolumn{2}{|c|}{$\begin{array}{r}\text { Umidade relativa }(\%) \\
\text { Relative humidity (\%) }\end{array}$} \\
\hline & $\begin{array}{l}\text { Mínima } \\
\text { Minimum }\end{array}$ & $\begin{array}{l}\text { Máxima } \\
\text { Maximum }\end{array}$ & $\begin{array}{l}\text { Mínima } \\
\text { Minimum }\end{array}$ & $\begin{array}{l}\text { Má } \\
\text { Max }\end{array}$ \\
\hline 2 & $\begin{array}{r}25,3 \pm \\
\quad(25\end{array}$ & $\begin{array}{l}30,6 \pm 1,6 \\
\quad(32)^{1}\end{array}$ & $\begin{array}{l}62,2 \pm 7,0 \\
(55)^{1}\end{array}$ & $\begin{array}{l}75,8 \pm 3,5 \\
(80)^{1}\end{array}$ \\
\hline 9 & $\begin{array}{l}27,0 \pm 1,18 \\
(27)^{1}\end{array}$ & $\begin{array}{c}30,5 \pm 2,7 \\
(33)^{1}\end{array}$ & $\begin{array}{l}60,2 \pm 9,0 \\
\quad(50)^{1}\end{array}$ & $\begin{array}{c}78,0 \pm 2,5 \\
(81)^{1}\end{array}$ \\
\hline $6-4$ & $\begin{array}{l}26,3 \pm 1,27 \\
(26)^{1}\end{array}$ & $\begin{array}{l}30,5 \pm 1,2 \\
\quad(32)^{1}\end{array}$ & $\begin{array}{l}57,4 \pm 4,0 \\
\quad(53)^{1}\end{array}$ & $\begin{array}{l}73,8 \pm 6,4 \\
(80)^{1}\end{array}$ \\
\hline Média & 26,2 & 30,5 & 60,0 & 75,8 \\
\hline
\end{tabular}

Average

${ }^{1}$ Valores mínimo e máximo de temperatura e umidade relativa obtido durante cada período.

${ }^{1}$ Minimum and maximum values of temperature and relative humidity obtained during each period.

Rev. bras. zootec., 30(6S):2021-2025, 2001 
Tabela 4 - Efeito da relação arginina:lisina digestível sobre o desempenho de frangos de corte Table 4 - Effect of digestible arginine:lysine ratio on performance of broilers

\begin{tabular}{|c|c|c|c|c|}
\hline $\begin{array}{c}\text { Relação } \\
\text { Arg:lis dig. } \\
\text { Arginine:lysine } \\
\text { digestible ratio }\end{array}$ & $\begin{array}{c}\text { Peso aos } 42 \text { dias } \\
\text { Average weight } 42 \text { days }\end{array}$ & $\begin{array}{c}\text { Ganho de peso } \\
\text { Weightgain }\end{array}$ & $\begin{array}{l}\text { Consumo de ração } \\
\text { Feed intake }\end{array}$ & $\begin{array}{c}\text { Conversão alimentar } \\
\text { Feed:gain ratio }\end{array}$ \\
\hline$(\%)$ & (g) & (g) & (g) & $(g / g)$ \\
\hline 95,0 & 2,285 & 1,591 & 2,941 & 1,848 \\
\hline 102,5 & 2,306 & 1,612 & 2,957 & 1,834 \\
\hline 110,0 & 2,345 & 1,633 & 2,996 & 1,812 \\
\hline 117,5 & 2,312 & 1,620 & 2,961 & 1,828 \\
\hline 125,0 & 2,310 & 1,618 & 2,978 & 1,840 \\
\hline 132,5 & 2,315 & 1,622 & 2,948 & 1,817 \\
\hline Média & 2,312 & 1,616 & 2,964 & 1,830 \\
\hline Average & & & & \\
\hline Regressão & - & NS & NS & NS \\
\hline Regression & & & & \\
\hline $\mathrm{CV}(\%)$ & - & 2,671 & 1,963 & 1,581 \\
\hline
\end{tabular}

Tabela 5 - Efeito da relação arginina:lisina digestível sobre a qualidade da carcaça de frangos de corte Table 5 - Effect of digestible arginine:lysine ratio on carcass quality of broilers

\begin{tabular}{|c|c|c|c|c|c|c|}
\hline \multirow[b]{2}{*}{$\begin{array}{l}\text { Relação } \\
\text { arg:lis dig. } \\
(\%) \\
\text { Arg:lys } \\
\text { Dig. ratio }\end{array}$} & \multicolumn{5}{|c|}{$\begin{array}{l}\text { Qualidade de carcaça } \\
\text { Carcass quality }\end{array}$} & \multirow[b]{2}{*}{$\begin{array}{c}\text { Rendimento de } \\
\text { gordura }(\%) \\
\text { abdominal }(\mathrm{GA}) \\
\text { Abdominal } \\
\text { fat }(A F)\end{array}$} \\
\hline & $\begin{array}{l}\text { Peso de } \\
\text { abate }(\mathrm{g}) \\
\text { Average } \\
\text { slaughter } \\
\text { weight }\end{array}$ & $\begin{array}{c}\text { Rendimento de } \\
\text { carcaça }(\%) \\
\text { Carcass } \\
\text { yield }\end{array}$ & $\begin{array}{l}\text { Rendimento de } \\
\text { perna }(\mathrm{RP})(\%) \\
\text { Leg quarter } \\
\text { yield }(L Q)\end{array}$ & $\begin{array}{c}\text { Rendimento de } \\
\text { peito }(\%) \\
\text { Breast meat } \\
\text { yield }\end{array}$ & $\begin{array}{l}\text { Rendimento de } \\
\text { filé de peito }(\%) \\
\text { Breast meat } \\
\text { fillet yield }\end{array}$ & \\
\hline 95,0 & 2,278 & 68,503 & 30,502 & 31,390 & 22,765 & 3,027 \\
\hline 102,5 & 2,308 & 69,231 & 31,034 & 31,063 & 22,934 & 3,176 \\
\hline 110,0 & 2,348 & 68,114 & 30,564 & 31,431 & 22,773 & 3,028 \\
\hline 117,5 & 2,308 & 68,399 & 31,024 & 31,364 & 23,072 & 2,942 \\
\hline 125,0 & 2,322 & 68,845 & 30,759 & 31,425 & 23,145 & 3,018 \\
\hline 132,5 & 2,319 & 68,050 & 31,424 & 31,575 & 23,401 & 2,851 \\
\hline $\begin{array}{l}\text { Média } \\
\text { Average }\end{array}$ & 2,314 & 68,524 & 30,885 & 31,375 & 23,015 & 3,007 \\
\hline $\begin{array}{l}\text { Regressão } \\
\text { Regression }\end{array}$ & - & NS & $\mathrm{L} * *$ & NS & $\mathrm{NS}$ & $\mathrm{L}^{*}$ \\
\hline $\mathrm{CV}$ & - & 1205 & 1642 & 2650 & 3436 & 8077 \\
\hline
\end{tabular}

$L^{*}$ Efeito linear $(P<0,05)\left(L^{*}\right.$ Linear effect $\left.[P<.05]\right) . \quad R P(L Q)-L^{* *}-y=28,5037+0,0208825 x ; R^{2}=0,66$

$L^{* *}$ Efeito linear $(P<0.01)\left(L^{* *}\right.$ Linear effect $\left.[P<.01]\right) . \quad G A(A F)-L^{*}-y=3,78492-0,00696317 x ; R^{2}=0,52$

NS Não-significativo (NS Not significant).

MENDES et al. (1997) também observaram redução linear $(\mathrm{P}<0,05)$ da gordura abdominal das aves, com o aumento da relação Arg:Lis em condições de alta temperatura ambiente.

\section{Conclusões}

A relação Arg:Lis não influenciou o desempenho de frangos de corte em altas temperaturas.
Entretanto, o aumento dessa relação melhorou linearmente o rendimento de perna e diminuiu a deposição de gordura abdominal.

\section{Referências Bibliográficas}

ALLEN, N.K., BAKER, D.H., 1972. Effects of excess lysine on the utilization and requirement for arginine by the chick. Poult. Sci. 51:902-906.

AUSTIC, R.E., 1981. On the nature of amino acid interactions.

Rev. bras. zootec., 30(6S):2021-2025, 2001 
In: Cornell Nutrition Conference, 1981, Ithaca. Proceedings... Ithaca: Cornell University.

BAKER, D.H., MOLITORIS, R. A., 1991. Partioning of nutrients for growth and other metabolic functions: Efficiency and priority considerations. Poult. Sci. 70:1797-1805.

BRAKE, J., BALNAVE, D., DIBNER, J.J., 1998. Optimum dietary arginine:lysine ratio for broiler chickens is altered during heat stress in association with changes in intestinal uptake and dietary sodium chloride. Brit. Poult. Sci. 39:639-647.

EDMONDS, M.S., PARSONS, C.M., BAKER, D.H. 1985. Limiting amino acid in low-protein corn-soybean meal diets feed to growing chicks. Poult. Sci., 64:1519-1526.

LEESON, S., 1986. Nutritional considerations of poultry during heat stress. World's Poult. Sci. J., 42:69-81.

MACK, S., BERCOVICI, D., DE GROOTE, G. et al. 1999. Ideal amino acid profile and dietary lysine specification for broiler chickens of 20 to 40 days of age. Brit. Poult.Sci. , 40:257-265.

MENDES, A.A., WATKINS, S.E., ENGLAND, J.A. et al. 1997. Influence of dietary lysine levels and arginine:lysine ratios on performance of broilers exposed to heat or cold stress during the period of three to six weeks of age. Poult. Sci., 76:472-481.
NATIONAL RESEARCH COUNCIL - NRC. 1994. Nutrient requirements of poultry. 9.rev.ed. Washington, DC.: National Academy Press.

ROSTAGNO, H.S., ALBINO, L.F.T., DONZELE, J.L. et al. 2000. Tabelas brasileiras para aves e suínos. Composição de alimentos e exigências nutricionais. Viçosa: UFV. 141p.

SMITH, M.O. 1993a. Parts yield of broilers reared under cycling high temperatures. Poult. Sci., 72:1146-1150.

UNIVERSIDADE FEDERAL DE VIÇOSA - UFV. 1983. Central de Processamento de Dados - UFV - CPD. SAEG Sistema para analise estatística e genética. Viçosa-MG. 59p.

Recebido em: 15/12/00

Aceito em: 21/08/01 